\section{Commentary: Women wielding saws and cardiothoracic surgery}

\author{
Elizabeth H. Stephens, MD, PhD
}

\begin{abstract}
"You really want to saw people's chests open everyday?!!" I was a very junior resident and had already clearly staked my claim, as it were, in cardiac surgery - eventually congenital cardiac surgery, if all went well. This was a beloved general surgery attending whom we all respected, quite senior and very invested in resident education, having mentored many trainees over the years. I knew he had encouraged the guys further along than me within cardiothoracic training, and because of this I was struck by the comment-was this because I didn't fit the preconceived mold of a cardiac surgeon? I presumed he had counseled the guys to yes, go ahead and "saw people's chests open." The comment jarred me to say the least and prompted introspection. Did I have what it took-not in terms of the technical ability, intellectual knowledge, or clinical aptitude-but that level of grit and assertiveness required for the demands of a cardiac surgery career? That introspection was important for me, because I still had years ahead of me in training and was facing the prospect of a very challenging, albeit rewarding, career. Would I have what it takes? Just one comment among the many, forming the milieu that a woman entering cardiac surgery faces, and gives perspective to the report by Servito and colleagues. ${ }^{1}$

In this brief research report, ${ }^{1}$ the relative proportion of women among trainees and attending cardiac surgeons in Canada from 1998 to 2020 was analyzed. They report an increase in the proportion of female applicants to cardiac surgery from $14 \%$ to $47 \%$ during that time period, with an equal match rate for men and women. ${ }^{1}$ Women in leadership positions including program directors and division
\end{abstract}

\footnotetext{
From the Department of Cardiovascular Surgery, Mayo Clinic, Rochester, Minn. Disclosures: The author reported no conflicts of interest.

The Journal policy requires editors and reviewers to disclose conflicts of interest and to decline handling or reviewing manuscripts for which they may have a conflict of interest. The editors and reviewers of this article have no conflicts of interest.

Received for publication June 15, 2021; revisions received June 15, 2021; accepted for publication June 16, 2021; available ahead of print June 23, 2021.

Address for reprints: Elizabeth H. Stephens, MD, PhD, Department of Cardiovascular Surgery, Mayo Clinic, 200 First St, SW, Rochester, MN 55905 (E-mail: stephens. elizabeth@mayo.edu).

J Thorac Cardiovasc Surg 2022;163:e207-8

$0022-5223 / \$ 36.00$

Copyright (c) 2021 by The American Association for Thoracic Surgery

https://doi.org/10.1016/j.jtcvs.2021.06.028
}

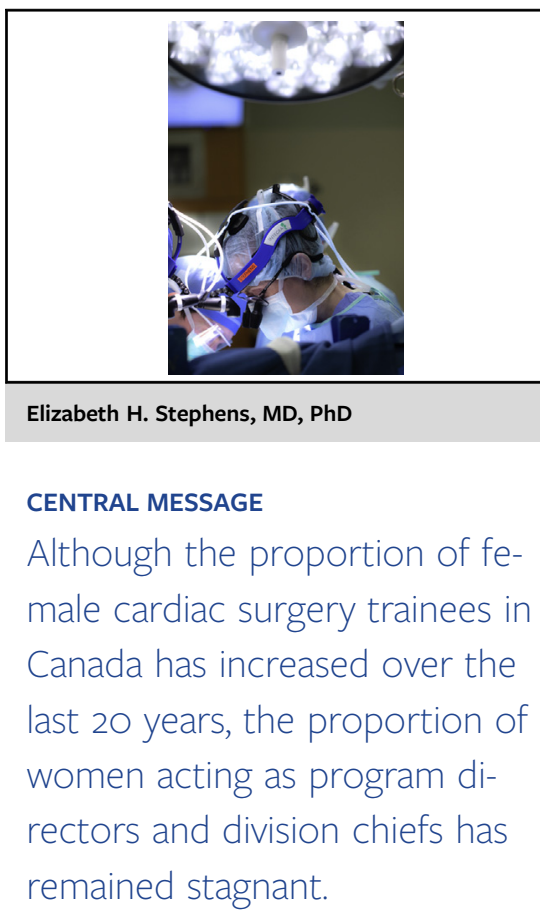

chiefs have not changed, with women comprising $8 \%$ of program directors and $6 \%$ of division chiefs. ${ }^{1}$

What do we take away from these data? The good news is that women who choose to enter the field are matching at similar rates to men, and there is increasing interest by women in the field overall, but the lack of increase in women appointed to leadership roles is concerning. The data presented by Servito and colleagues ${ }^{1}$ add to the accumulating body of literature on gender in our specialty. Although even as recently in mid-2000 gender was a taboo subject, this topic has received increased attention over the last decade. Indeed, the first step to addressing a problem is recognizing its existence. Challenges for women entering cardiothoracic surgery occur at all points along the pipeline. In terms of attracting women to the field, concerns about lifestyle, lack of role models and mentorship, and a general culture not supportive to women in the specialty contribute to discouraging women from entering the field. ${ }^{2}$ A recent survey of Society of Thoracic Surgeons members enumerated this cultural milieu and demonstrated that men perceived the milieu as more supportive of women than women did. ${ }^{3}$ Bias, both conscious and unconscious, also plays a role, with studies as recent as 2010 reporting male surgeons less likely to agree that surgery is a good career for women. ${ }^{4}$ Although studies in cardiothoracic surgery have found female residents to be equally satisfied with career choice and to have a similar number of interviews 
and job offers compared with male residents, they felt less prepared technically and for practicing independently. ${ }^{5}$ Studies in other surgical specialties demonstrate women are less likely to become board certified ${ }^{6}$ and more likely to experience burnout, ${ }^{7}$ highlighting the challenges for women during training. Women who do become attendings face challenges as they build a practice, with studies demonstrating that physicians are less likely to refer to female surgeons and female surgeons are more likely to experience retributions after a complication than male surgeons, ${ }^{8}$ despite females demonstrating better outcomes overall. ${ }^{9}$ Difficulties continue throughout their career, with women not progressing to leadership positions, remaining significantly underrepresented among editorial boards and in conferences, and less likely to receive funding, to name a few. ${ }^{10}$

With the many challenges that women face, where do we go from here? Progress has been made, as demonstrated by the increase in female cardiac surgery residents in Canada, but the study highlights the lack of progression of women to positions of leadership. ${ }^{1}$ Clearly, there are many factors that affect the decision for women to pursue leadership positions as well as eligibility of women for such positions; delayed childbearing among women and their desires related to home life as well as the time lag between increasing female trainees and a pool of female candidates for leadership positions likely contribute. ${ }^{11}$ Various organizations within our specialty, such as the American Association for Thoracic Surgery, Society for Thoracic Surgery, and Women in Thoracic Surgery, are actively working to increase female and minority representation in leadership roles and train a new generation of female leaders with the resilience to rise above the daily grind of bias, microagressions, and at times frank harassment that women continue to face. We also can learn from other surgical specialties and institutions that have enacted measures to address barriers and have demonstrated improvement. ${ }^{10}$ Our patients, staff, and the public at large have long-held expectations that will take an extended time to change, but we have an opportunity within our specialty to create a better future for women entering the field. In the meantime, women and minorities entering the field still must work harder, are under more scrutiny, and must prove themselves while carrying additional baggage due to our minority status. We follow in the footsteps of the generation before us who truly were the trailblazers paving the way for the current generation. People will still make disheartening remarks discouraging us in the journey, but we must look for allies along our path and improve the path for those behind us.

\section{References}

1. Servito M, Ouzounian M, Chung J, Yanagawa B. Trends in female cardiac surgery trainees and staff in Canada: 1998 to 2020. J Thorac Cardiovasc Surg. 2022;163:e203-6.

2. Vaporciyan AA, Reed CE, Erikson C, Dill MJ, Carpenter AJ, Guleserian KJ, et al. Factors affecting interest in cardiothoracic surgery: survey of North American general surgery residents. Ann Thorac Surg. 2009;87:1351-9.

3. Ceppa DP, Dolejs SC, Boden N, Phelan S, Yost KJ, Edwards M, et al. Gender bias and its negative impact on cardiothoracic surgery. Ann Thorac Surg. 2020;109: 14-7.

4. Ahmadiyeh N, Cho NL, Kellogg KC, Lipsitz SR, Moore FD Jr, Ashley SW, et al. Career satisfaction of women in surgery: perceptions, factors, and strategies. $J$ Am Coll Surg. 2010;210:23-8.

5. Stephens EH, Robich MP, Walters DM, DeNino WF, Aftab M, Tchantchaleishvili V, et al. Gender and cardiothoracic surgery training: specialty interests, satisfaction, and career pathways. Ann Thorac Surg. 2016;102:200-6.

6. Yeo HL, Abelson JS, Symer MM, Mao J, Fabrizio Michelassi F, Bell R, et al. Association of time to attrition in surgical residency with individual resident and programmatic factors. JAMA Surg. 2018;153:511-7.

7. Elmore LC, Jeffe DB, Jin L, Awad MM, Turnbull IR. National survey of burnout among US general surgery residents. J AM Coll Surg. 2016;223:440-51.

8. Sarsons H. Interpreting Signals in the Labour Market: Evidence from Medical Referrals. Cambridge, MA: Harvard University; 2017.

9. Wallis CJD, Ravi B, Coburn N, Nam RK, Detsky AS, Satkunasivam R. Comparison of postoperative outcomes among patients treated by male and female surgeons: a population based matched cohort study. BMJ. 2017;359:j4366.

10. Stephens EH, Heisler CA, Temkin SM, Miller P. The current status of women in surgery: how to affect the future. JAMA Surg. 2020;155:876-85.

11. Pham DT, Stephens EH, Antonoff MB, Colson YL, Dildy GA, Gaur G, et al. Birth trends and factors affecting childbearing among thoracic surgeons. Ann Thorac Surg. 2014;98:890-5. 